\title{
Improving Environmental Policy-Making Process to Enable Achievement of Sustainable Development Goals
}

\author{
Noora Adnan Almannaei ${ }^{\mathrm{a}}$, Mohammad Salim Akhter ${ }^{\mathrm{a}}$ and Afzal Shah ${ }^{\mathrm{b}, *}$ \\ ${ }^{a}$ Department of Chemistry, College of Science, University of Bahrain, Sakhir, Bahrain \\ ${ }^{\mathrm{b}}$ Departments of Chemistry: University of Bahrain and Quaid-i-Azam University, Islamabad, Pakistan
}

\begin{abstract}
This article addresses the continuing quest for effective sustainable development laws, policies and other measures, in the context of the international objective of achieving the UN Sustainable Development Goals by 2030. It addresses these issues both in general and in the specific context of climate policy. It focuses on exploring the results presented by other authors that discuss these matters in depth, with particular attention to the five problem areas: uncertainties in dealing with concerns of precaution and possible future impacts; the role of nature in society; international treaties; interlinkages among the SDGs; and the challenges of evaluation and feedback.
\end{abstract}

Keywords: Sustainable development law, sustainable development policy, UN sustainable development goals, SDGs, climate law and policy, laws addressing uncertainty, the role of nature in society, international environmental treaties, evaluation and feedback

Over the years, policy-makers have been working towards creating effective measures for sustainable development. Without a strategic plan, this effort would not have shown any significant advancement. When discussing the relationship between governmental policy-making and achieving the UN-adopted Sustainable Development Goals (SDGs), ${ }^{1}$ both Joshi et al. and Dong and Hauschild agreed that various aspects of this relationship need to be assessed and that this has been a challenge especially in terms of providing rational, coherent and transparent support for sustainable development (Joshi et al., 2015; Dong and Hauschild, 2017). Many of these assessments, however, require scientific support. For example, the importance (in seeking to achieve the SDGs) of nature's contributions and values to the people must be taken into consideration (Anderson et al., 2018). Decision-making on sustainable development requires scientific information (Dong

\footnotetext{
*Corresponding author. E-mail: ashah@uob.edu.bh and afzals_ qau@yahoo.com.
}

and Hauschild). Others, too, have agreed that the relationship between humans and nature must be studied and managed in the science-policy platform (Carpenter et al., 2009; Dong and Hauschild).

Too often, the policy domains of agriculture, energy, environment and finance (all mentioned in the SDGs) are treated separately. Effective policy-making, however, requires that institutions move beyond simple checklists and study further consequences. For example, while expanding agriculture may lead to robust food production, it may also degrade cultural and natural elements. Thus, a study of the interconnections among SDGs is very important.

Kumar et al. (2018) highlighted the importance of developing a hierarchical model as a tool to assist in policy-making with regard to specific SDGs, especially in the least developed countries. In addition, there are some key questions that need to be addressed when considering the sustainability of an existing system. Among these are the following (for each system): 
- What system is to be protected?

- Where is the system boundary?

- What timescale should apply?

- What level of system quality needs to be maintained or improved?

(Dong and Hauschild).

Indicators are needed simply to answer the most basic operational question: "How will we know objectively whether things are getting better or worse?" (Lawrence, 1997). Joshi et al. suggested the use of a long-term dynamic modelling system; however, that study did not take all of the SDGs into consideration. Costanza et al. developed an approach that clarifies the relationship between SDGs (Costanza et al., 2016a). This modelling approach is used as a sustainable wellbeing index that explores economic, environmental and social contributions, and uses a hybrid approach that integrates this index with the SDGs to determine future policy scenarios.

During their development, it was noted that the process of formulating SDGs should be based on three considerations:

(a) The need to embrace an integrated social-ecological system perspective,

(b) The importance of addressing trade-offs between the ambition of goals and the feasibility in reaching them, and

(c) The need to be guided by existing knowledge about the principles, dynamics and constraints of social change processes, domestically as well as globally

(Norström et al., 2014).

Following their adoption, scholars have gone on to suggest that, in order to achieve the SDGs, policymakers as well as scientists must clarify how goals and targets interconnect (Costanza et al., 2016b).

It is also necessary to consider the relationship between the extreme vulnerability of nature and national environmental performance. Eisenstadt et al. compared environmental performances across the globe to address why some countries seem to be more "green" than others (Eisenstadt et al., 2018). Payne suggested that public opinion and the free flow of information promote the creation of environmental advocacy groups which in turn encourage environmental legislation (Payne, 1995). This does not necessarily mean that democracies show the best environmental performance, but it does suggest that more attention should be focused on the vulnerabilities that cause some countries to be more challenged by particular environmental issues.

In this connection, it is important to take international environmental treaties and conventions into consideration, especially when considering implementation by countries which view themselves as bound by the 2030 Agenda for Sustainable Development. Saner et al. (2019) suggested that a thorough examination of international agreements and treaties be conducted, in order to promote the implementation of the 2030 Agenda. For example, a comparison between implementation concerns regarding Agenda 21 and the 2030 Agenda, and the identification of linkages between the two could be valuable. In this process, it would be important to highlight the uncertainties that influence the process of policy-making (Puig and Bakhtiari, 2019). In particular, incorporating uncertainties into the policy-making process is essential for designing and implementing effective climate change and other environmental policies (Morgan, 2009). The current article covers all these aspects of policy framing.

\section{Methodology}

Many factors need to be examined in order to effectively implement policies. This article focuses on exploring the results presented by other authors that discuss in depth the field of improving the process of policy-making in order to achieve SDGs by 2030 . Environmental policies that focus on solving environmental issues, such as climate change, pollution and global warming, need to be explored particularly to identify gaps to fill and reach a model that can help countries to achieve their environmental goals. Each of the studies referred to in this article looked at environmental policy-making from a different angle. The authors felt that combining all of these angles in one study would contribute to further improvement and that such a study could be used as a reference of policy tools and models.

\section{Results and Discussion}

Environmental policy focuses on the need to manage human activities with a view to preventing, 
reducing or mitigating harmful effects on nature and natural resources, as well as ensuring that man-made changes to the environment do not have harmful effects on humans or the environment (McCormick, 2001). Over the years, the priority given to each environmental issue has sometimes increased and sometimes diminished. Even after a particular issue's importance has declined, the implications of the continued existence of that issue may increase, a situation that is problematic to policy-makers. Graff-Zivin and Krumholz stated that "individuals, firms, and governments make choices based on the costs that they will incur and the benefits they are expected to reap, but generally ignore the consequences of those decisions on others outside of their decision-making purview" (Graff-Zivin and Krumholz, 2018). In those situations, the absence of government intervention has led to excessive levels of environmental degradation and failure to secure a sustainable environment. This, therefore, is the reason that governments provide funding for environmental policies and their implementation. If countries continue to disregard the environment, it may reach a point where it will no longer be habitable.

While the functions of policy-making are clear in theory, their use and effectiveness are shaped by many practical constraints: technology, capacity, politics and economy. One of the main challenges that the world faces in the 21 st century is the design of policies that could translate environmental issues most effectively in the balance of economic growth and sustainability.

A recent study by the UN Economic and Social Commission for Asia and the Pacific warned that not a single Asian/Pacific country is on track to achieve any of the SDGs by 2030 (UN ${ }^{\circ}$ ESCAP, 2019). Although reporting some progress in curbing poverty (SDG 1), improving the quality of education (SDG 4) and achieving clean energy (SDG 7), the report states that efforts are not moving fast enough to achieve the targets by 2030 . According to the report, the best way to improve their chances of achieving SDGs in the short time that is left until 2030 is through strengthening environmental protection and the means of implementing the goals (SDG 17).

A 2018 editorial in the science magazine Nature Sustainability indicated that a number of assessment tools had been developed to measure the progress made towards achieving the SDGs, such as the official
231 SDG indicators and voluntary reports submitted by governments. Yet progress remains slow due to the geographical, political and economic challenges and factors that need to be considered in taking action and assessing success.

In 2017, the top performing countries included Sweden, Denmark and Norway. Not unexpectedly, the poorest countries were at the bottom of the list due to the demanding nature of some of the SDGs, which, inter alia, call for an end to poverty and hunger, and equality and universal access to healthcare and education (Willige, 2017). These demands are not as difficult for rich and developed countries like Sweden, Denmark and Norway as for poorer countries, nor do they demand major changes in governmental priorities. Sweden, for example, has shown a longstanding commitment to environmental issues. Economic performance reports indicate that Sweden's well-balanced environmental policies offer opportunities and lessons that the world could learn from, including taxes on environmentally harmful activities (OECD, 2014).

$\mathrm{Lu}$ argued that strengthening environmental protection will help address negative trends that limit the application of environmental policies to various issues ( $\mathrm{Lu}, 2019)$. He considered that no country is capable of achieving all the SDGs by 2030 on their own, and therefore stressed the importance of global partnerships, maximising the means of implementing SDGs which include "tax revenue, debt sustainability, sound policy, technology, favorable trade conditions and international cooperation".

\section{Uncertainties in Environmental Policy}

The first element of this analysis is the uncertainties in environmental policy-making. Puig and Bakhtiari argued that insufficient study and attention has been devoted to the need for and means by which scientists communicate the existence of uncertainty and characterise that uncertainty in the course of informing decision-makers on climate issues. Given the complexity of climate change management, it is important to incorporate uncertainty into the policy-making process and the design and implementation of effective environmental policies (Morgan). Table 1 shows the final results reported by Puig and Bakhtiari after analysing research gaps in this regard. 
Table 1

Research gaps for incorporating uncertainty in national-level climate-change-management policy

\begin{tabular}{llc}
\hline Topic & State of research today & Potential research priorities \\
\hline Characterizing uncertainty & $\begin{array}{c}\text { Conceptual framework for use in } \\
\text { computer-based models }\end{array}$ & $\begin{array}{c}\text { Broader framework, catering to both } \\
\text { computer-based and other types of } \\
\text { models } \\
\text { Quantifying uncertainty }\end{array}$ \\
Reducing uncertainty & $\begin{array}{c}\text { Protocol suitable for multi-criteria } \\
\text { decision analysis } \\
\text { Puit the specificities of key sectors }\end{array}$ & $\begin{array}{c}\text { Protocols for other types of } \\
\text { decision-support tools }\end{array}$ \\
Communicating uncertainty & $\begin{array}{c}\text { Application of the protocol to different } \\
\text { types of policy-planning processes, to } \\
\text { build a body of knowledge in this area }\end{array}$ \\
Reflecting uncertainty in the design of policies & $\begin{array}{c}\text { Review of the extent to which Swedish } \\
\text { climate-change-management policies } \\
\text { reflect uncertainty }\end{array}$ & $\begin{array}{c}\text { Aditional reviews, to improve } \\
\text { methodologies and foster the } \\
\text { integration of uncertainty in policy } \\
\text { design }\end{array}$ \\
\hline
\end{tabular}

Source: Puig et al., 2018.

A protocol for clearly communicating the existence and levels of uncertainties has reportedly been developed with the specific objective of promoting accurate communication between scientists and policy-makers (Fischhoff and Davis, 2014). More research is needed to analyse whether and how national-level policy-making on climate change management and other environmental issues is improving as a result of improvements in this type of communication.

\section{The Role of Nature}

Another important area of consideration relates to nature's importance to human lives. Nature's role in one society differs from that role in another, but it is undoubtedly important to consider this question as a key determinant in assessing the alteration in national policies that will be needed in order to achieve the SDGs.

Rolston identified ten areas of value related to nature:

1. economic value

2. life support value

3. recreational value

4. scientific value

5. aesthetic value

6. life value

7. diversity and unity values

8. stability and spontaneity values

9. dialectical value, and

10. sacramental value

(Rolston, 1981).
The study conducted by Anderson et al. shows that there is a significant relationship between "nature's contributions to people" and the SDGs, and that this relationship should be taken into account when formulating environmental policies. The authors argue that where policy incorporates awareness of nature's contributions to humans, it better demonstrates its relevance to numerous aspects of environmental development. After comparing each category of nature's contributions with the SDGs, they conclude that goals that deal with issues like education, inequalities and justice (SDGs 4, 5, 8 and 10) are least relevant in terms of nature's contributions, whereas energy, industry, sustainable cities and climate action (SDGs 7, 9, 11 and 13) all have a clear connection with nature. Food security, poverty and responsible consumption (SDGs 1, 2, 12 and 15) are also issues that involve a clear contribution from nature (soils, pollination, habitats and food). SDG 3 was grouped with medical priorities, but also involves nature's contribution. Water-related clusters were linked with the regulation of water quality and quantity, and are closely connected to nature with regard to challenges such as ocean acidification and life under water (SDGs 6 and 14). Even SDGs that were not expected to have an explicit relationship to nature such as SDG 16 (Peace, Justice and Strong Institutions), and SDG 17 (Partnerships for the Goals), reflect a linkage with nature's contribution, if for no other reason than that these two goals have direct linkages with all of the SDGs.

Thus, after combining the results of the study, the authors suggest that it is necessary to communicate 
these plural perspectives of nature's values to stakeholders and policy-makers. Linking nature values with human wellbeing is important in order to develop policies. Anderson et al. highlighted the essential role of non-material contributions to human wellbeing and identified ways to create tools that are scientifically correct. Developing tools using the linkages between nature's contribution to the SDGs would not only benefit decision-making, but would also add to public knowledge. In this way, the linkage between the SDGs and the contribution of nature to humans could be established in a way that increases the understanding of all key policy stakeholders and involved governmental bodies. Wood et al. indicate that the importance of nature lies in food, water, habitats and carbon capture as well as a secondary role for water quality and regulation (Wood et al., 2018).

\section{International Treaties and Agreements}

Multilateral environmental treaties and agreements have an important influence on the achievement of the SDGs. A 2016 study by UNEP notes both direct and indirect references to multilateral agreements in SDGs and the targets adopted (UNEP, 2016). It documented that key multilateral environmental agreements such as the UN Convention on Biological Diversity, the Convention on International Trade in Endangered Species of Wild Fauna and Flora and the United Nations Framework Convention on Climate Change all link to the SDGs and their related goals. Aligning national policies with multilateral agreements could contribute significantly to achieving several, if not all, SDGs.

As Vogel noted, "the regulatory context at a national level affects the impact of soft law standards, including those produced through multi-stakeholders initiatives" (Vogel, 2010). However, countries' commitments to international agreements differ. Graff-Zivin and Krumholz argue that countries most affected by environmental threats are also the greatest producers of polluting products.

Several studies discuss the significance of international treaties in relation to the goal of achieving the SDGs. Saner et al. compared the content of the United Nations Agenda 21 and various environmental treaties. They argued that incongruence between the two is high due to the fact that some critical topics are not considered in some cases, while others are treated differently in the two documents. Agenda 21 has a strong environmental focus; the main gaps identified in the study are in areas relating to environmental sustainability (e.g., management of hazardous wastes, as well as agricultural and rural development).

At present, however, Agenda 21 remains very useful and is similar to other outcome documents, especially when countries attempt to reduce their environmental vulnerability and risks caused by climate change, land degradation or pollution. As shown by data collected in various studies, there are significant gaps in the thematic coverage of the SDGs, particularly in areas where knowledge and methods already exist. However, the data also show deficiencies in the adoption of domestic legislation to underpin the Rio principles and conventions. Saner et al. used a method that helps underline areas where policies in certain documents and laws fail to include international norms such as international treaties and conventions that are globally agreed upon (Saner et al.). They suggested that there is a lack of credible and independent international scrutiny and monitoring of domestic delivery of the desired results and argued that the international community failed to convert the original Rio Agenda into a language that would hold sway in the most powerful governmental bodies such as finance ministries.

Saner et al. also produced an analysis that demonstrated the relevance of international outcome agreements in environmental policy-making. In the context of international relations, partner countries can refer to these documents and agreements for ideas and to better articulate their environmental needs and provide solutions. By linking the contents of key international environmental treaties, they can begin to specify areas of weakness and provide technical specifications and recommendations. Saner et al. suggested that international environmental treaties could be used to strengthen the implementation of the SDGs and provide governments with the necessary alterations to their domestic laws.

The 2030 Agenda is universal and takes into consideration people's needs for generations to come. As such it could be taken as a model that prioritises people, the planet, prosperity, peace and partnership while tackling climate change. Thus, SDG-17 states the goals of strengthening the means 
of implementation of all the SDGs and revitalising the global partnership for sustainable development. An alliance of different stakeholders is required to bring about cooperation between businesses, civil society, and more importantly within government bodies. Comparison between international laws and domestic laws provides a guidance toolbox not only for diplomats but also for policy-makers and all other stakeholders seeking to implement these responsibilities.

\section{Interlinkages Among the SDGs}

In order to create effective policy tools, it is essential to review the interlinkages between the SDGs, especially those that relate to environmental issues. By design, all SDGs are linked to one another, forming an integrated set of global priorities and objectives. A guide produced by the International Council for Science explores these relationships and notes that "understanding the range of positive and negative interactions among SDGs is a key to unlocking their full potential at any scale, as well as to ensuring that progress made in some areas is not made at the expense of progress in others" (International Council for Science, 2017). As shown in the study by Kumar et al., there is a significant relationship between the level of relationship between SDGs and how they complete one another.

After examining these interrelationships using interpretive structural modelling, that guide developed a structural model and a comparison of the SDGs. It identified goals with stronger correlations as "key" goals. It is important for developing and least developed countries to understand the level of interaction among the goals and how they influence one another in order to create effective policies. Le Blanc indicated that the SDGs and their associated targets can be seen as a network, in which links among the SDGs are noted through targets that explicitly refer to multiple other SDGs that were essentially made by the political process that created the goals (Le Blanc, 2015). As a result, "the political framework that the SDGs provide does not explicitly reflect the multiplicity of links that matter for policy purposes" (Le Blanc). It is essential to analyse goals and their linkages with one another in order to understand how to apply environment-related SDGs through the policy-making process.
Fredman et al. made a similar argument, suggesting that issues like gender equality are linked with multiple SDGs, and appraising the relationships between nine SDG targets (Fredman et al., 2016). They argued that particular goals cannot be fully achieved without addressing other linked goals. If a basic goal and its target are achieved, then policy-makers can continue from it, going on to create policies to achieve the more general goals. General targets cannot be entirely achieved without deciding related issues.

\section{Evaluation}

Evaluation plays a key role in all stages of the policy process. For our purposes, those stages were described by Khan and Rahman as follows: the policy process starts with problem identification and moves through a cycle of policy formulation and implementation (Khan and Rahman, 2017). The assessment process feeds into the development of environmental policies by contributing to the cycle. Bennear and Coglianese argued that the policy process begins with recognising key potential environmental problems and comprises the responses made by policy-makers to solve these issues (Bennear and Coglianese, 2005).

Policy programme evaluation seeks to determine the impact of a chosen policy or strategy after it has been adopted. Environmental policies must be evaluated after being implemented in order to consider appropriate improvement measures and identify hurdles in policy application. The goal of evaluation is to go beyond simple correlation to estimate the causal effects of the treatment on the outcomes selected for the study (Bennear and Coglianese).

The development of policy evaluation in environmental areas, however, has been relatively slow compared to that of other policy realms (Mickwitz, 2003). Environmental issues have key complex features such as their long-term impacts and vast geographically remote regions which should be taken into consideration during the evaluation of the policy instruments used to address them. It has been argued that "if evaluation of environmental policy is undertaken without due consideration of these specifics involved, there is a great risk of identifying only minor impacts and low effectiveness" (Mickwitz). 
After examining different areas of policy evaluation, a study by Russel et al. showed that interviewees on environmental policy evaluations indicate concerns about the dominance of economics in the appraisal process and the related push for enhanced monetary valuation of environmental impacts (Russel et al., 2018). Problems of differing professional interpretations and disciplinary perspectives are perhaps exacerbated by the different logics of the academic professionals who, although generally focused on defining and measuring impacts of decisions on the environment, often differ from the policy-making professionals who have to apply environmental knowledge to real-world policies.

Increased understanding of the different levels of logic can help improve environmental policy appraisal. Even though there are integration problems, these problems might be specific to the different types of appraisal and governance. There is an important role that institutions can play in relation to the operation of policy appraisal and policy integration. The study does not find alternatives, but it argues that understanding different logics can help with improving appraisal as a tool for integrative governance.

\section{Conclusion}

Policy-making is a complex process demanding many aspects to be examined in order to create an effective scientific model that would be able to solve environmental issues and ensure sustainability. There are three specific ways to improve environmental policy-making. The first is concerned with the analysis of the significant relationship between SDGs and nature's contributions to human lives. The second is to address the areas where domestic laws and national policy programmes interlink with international treaties - climate change and environmental problems are global issues and therefore global governance must be taken into consideration when creating environmental policies. The third involves finding the relationship between SDGs in order to implement them effectively (i.e., where one SDG is dependent on achieving another SDG); this must be taken into consideration when developing environmental policies. In order to identify and understand the gaps, a thorough examination of existing literature and research on the topic is important, so that new work will build upon that which has gone before and add to scientists' previous findings and existing models. By studying the different interpretations of authors in recent years and combining different policy strategies, an effective plan can be framed. Many aspects remain, which need to be further examined when developing a policy structure to implement SDGs.

\section{References}

Anderson, C.B., Seixas, C.S., Barbosa, O., Fennessy, M.S., Diaz-José, J. and Herrera-F., B. 2018. "Determining nature's contributions to achieve the sustainable development goals". Sustainability Science 14: 543-547.

Bennear, L.S. and Coglianese, C. 2005. "Measuring Progress: Program Evaluation of Environmental Policies". Environment: Science and Policy for Sustainable Development 47(2): 22-39.

Carpenter, S.R., Mooney, H.A., Agard, J., Capistrano, D., DeFries, R.S., Díaz, S., Dietz, T., Duraiappah, A.K., Oteng-Yeboah, A., Pereira, H.M., Perrings, C., Reid, W.V., Sarukhan, J., Scholes, R.J. and Whyte, A. 2009. "Science for managing ecosystem services: Beyond the Millennium Ecosystem Assessment". Proceedings of the National Academy of Sciences of the United States of America (PNAS) 106: 1305-1312.

Costanza, R., Daly, L., Fioramonti, L. et al. 2016a. "Modelling and measuring sustainable wellbeing in connection with the UN Sustainable Development Goals". Ecological Economics 130: 350-355.

Costanza, R., Daly, L., Fioramonti, L. et al. 2016b. "The UN sustainable development goals and the dynamics of well-being”. Solutions 7(1): 20-22.

Dong, Y. and Hauschild, M.Z. 2017. "Indicators for Environmental Sustainability". Procedia CIRP 61: 697-702.

Editorial (unsigned). 2018. "Tracking progress on the SDGs". Nature Sustainability 1(8): 377. Available at https://www.nature.com/articles/s41893-018-0131-z.pdf.

Eisenstadt, T.A., Fiorino, D.J. and Stevens, D. 2018. "National environmental policies as shelter from the storm: specifying the relationship between extreme weather vulnerability and national environmental performance". Journal of Environmental Studies and Sciences 9(1): 96-107.

Fischhoff, B. and Davis, A.L. 2014. "Communicating scientific uncertainty". PNAS 111(4): 13664-13671.

Fredman, S., Kuosmanen, J. and Campbell, M. 2016. "Transformative Equality: Making the Sustainable Development Goals work for women”. Ethics \& International Affairs 30(02): 177-187.

Graff-Zivin, J. and Krumholz, S. 2018. Environmental Policy-Making; Theory and Practice. Oxford: Rockefeller Foundation Economic Council on Planetary Health. Available at https://www.planetaryhealth.ox.ac.uk/wp-content/uploads/ sites/7/2018/06/Envtl-Policy-Making.pdf.

International Council for Science. 2017. A Guide to SDG Interactions: From Science to Implementation. Available at https://council.science/cms/2017/05/SDGs-Guide-to-Interacti ons.pdf. 
Joshi, D.K., Hughes, B.B. and Sisk, T.D. 2015. "Improving governance for the Post-2015 Sustainable Development Goals: Scenario forecasting the next 50 years". World Development 70: 286-302.

Khan, A.R. and Rahman, M. 2017. "The Role of Evaluation at the Stages of Policy Formulation, Implementation, and Impact Assessment". AGATHOS 8(1): 173-186.

Kumar, P., Ahmed, F., Kumar Singh, R. and Sinha, P. 2018. "Determination of hierarchical relationships among sustainable development goals using interpretive structural modeling". Environment Development and Sustainability 20(5): 2119-2137.

Lawrence. G. 1997. "Indicators for sustainable development". In: Dodds, F. The Way Forward: Beyond Agenda 21. London: Earthscan.

Le Blanc, D. 2015. "Towards integration at last? The sustainable development goals as a network of targets". UN Dept. of Economic and Social Affairs, Working Paper No. 141. Available at https://www.un.org/esa/desa/papers/2015/ wp141_2015.pdf.

Lu, J. 2019. "Asian Countries are Off Track to Achieve the Sustainable Development Goals". UN Dispatch, 7 June. Available at https://www.undispatch.com/asia-sdgs/.

McCormick, J. 2001. Environmental Policy in the European Union, at 21. The European Union Series. Basingstoke: Palgrave.

Mickwitz, P. 2003. "A Framework for Evaluating Environmental Policy Instruments: Context and Key Concepts". Evaluation 9(4): 415-436.

Morgan, M.G. 2009. Best practice approaches for characterizing, communicating and incorporating scientific uncertainty in climate decision making. U.S. Climate Change Science Program Synthesis and Assessment Product 5.2. Collingdale PA: Diane Publishing.

Norström, A.V., Dannenberg, A., McCarney, G., Milkoreit, M., Diekert, F., Engstrom, G., Fishman, R., Gars, J., Kyriakopoolou, E., Manoussi, V., Meng, K., Metian, M., Sanctuary, M., Schlüter, M., Schoon, M., Schultz, L. and Sjöstedt, M. 2014. "Three necessary conditions for establishing effective Sustainable Development Goals in the Anthropocene". Ecology and Society 19(3).

OECD. 2014. "Environmental performance review of Sweden: Assessment and recommendations". Available at https://www.oecd.org/env/country-reviews/sweden2014.htm.

Payne, R.A. 1995. "Freedom and the environment". Journal of Democracy 6(3): 41-55.
Puig, D. and Bakhtiari, F. 2019. "Incorporating uncertainty in national-level climate change-mitigation policy: possible elements for a research agenda". Journal of Environmental Studies and Sciences 9(1): 86-89.

Rolston, H. 1981. "Values in Nature". Environmental Ethics 3 113-128.

Russel, D., Turnpenny, J. and Jordan, A. 2018. "Mainstreaming the environment through appraisal: Integrative governance or logics of disintegration?" Environment and Planning C: Politics and Space 36(8): 1355-1370.

Saner, R., Saner-Yiu, L. and Kingombe, C. 2019. "The 2030 Agenda compared with six related international agreements: valuable resources for SDG implementation". Sustainability Science 2019: 1-32.

UN ESCAP (Economic and Social Commission for Asia and the Pacific). 2019. Asia and the Pacific SDG Progress Report 2019. Available at https://www.unescap.org/publications/asia -and-pacific-sdg-progress-report-2019.

UNEP. 2016. Enhancing Cooperation among the seven biodiversity related agreements and conventions at national level using the National Biodiversity Strategies and Action Plans. Nairobi: UNEP.

Vogel, D. 2010. "The Private Regulation of Global Corporate Conduct: Achievements and Limitations". Business and Society 49(1): 68-87.

Willige, A. 2017. "Which countries are achieving the UN Sustainable Development Goals fastest?" World Economic Forum, 20 March. Available at https://www.weforum.org/ agenda/2017/03/countries-achieving-un-sustainable-developm ent-goals-fastest/.

Wood, S.L.R., Jones, S.K., Johnson, J.A. et al. 2018. "Distilling the role of ecosystem services in the Sustainable Development Goals". Ecosystem Services 29: 70-82.

\section{Endnotes}

${ }^{1}$ [The SDGs were adopted on 21 October 2015 by the UN General Assembly as A/RES/70/1. The goals and all targets and means of implementation, as adopted, are presented online at https://sustainabledevelopment.un.org/?menu=1300. Following adoption, the SDGs were reviewed and discussed in Martinez, $C$. and Mueller, M. 2015. "The SDGs: Opportunities for Conservation". EPL 45(6): 239-246. Ed.] 